\title{
Zirconia Pressure Sensors: From Nanopowders to Device
}

\author{
R.R. Piticescu', M. Hrovath², D. Belavic ${ }^{3}$, A. Ionascu4, \\ B. Malic ${ }^{2}$, A. M. Motoc ${ }^{1}$ and C. Monty ${ }^{5}$ \\ ${ }^{1}$ Non-ferrous\&Rare Metals Institute, 102 Biruintei Blvd., 077145 Pantelimon-Bucharest, Romania \\ 2 Jozef Stefan Institute, Jamova 39, Ljubljana, Slovenia \\ ${ }^{3}$ HIPOT HYB Sentjernej, Slovenia \\ ${ }^{4}$ Company for Electronic and Electrotechnic Industry IPEE SA, Curtea de Arges, Romania \\ ${ }^{5}$ CNRS/Institute de Science et de Genie des Materiaux et Procedees, Font Romeu, France
}

\begin{abstract}
Keywords: (A) $\mathrm{Y}_{2} \mathrm{O}_{3}-\mathrm{ZrO}_{2}$ (B) $\mathrm{ZrO}_{2}-\mathrm{Al}_{2} \mathrm{O}_{3}$ (C) Synthesis (D) Tape casting (E) lonic Conductivity (F) Mechanical pressure gauge
\end{abstract}

\begin{abstract}
Yttria-doped zirconia nanopowders have been obtained using the hydrothermal procedure starting from soluble inorganic salts. The mechanisms and kinetics of the process have been studied to obtain high purity powders with a crystalline size range of 4 to $22 \mathrm{~nm}$ and specific surface near $200 \mathrm{~m}^{2} / \mathrm{g}$. These powders have been have been used to obtain membranes with controlled thickness and with densities over $95 \%$ of the theoretical value by employing the tape casting technique using organic binders, dispersants and surfactants. The influence of the additives and sintering regime on the density and microstructure of membranes has been studied. The ionic conductivity of the materials was investigated and modelled. Different types of ruthenate pastes were used to obtain thick resistive films on the zirconia membranes and interactions between the substrate and membranes were studied. Finally the gauge characteristics of the device and possibilities for applications as mechanical pressure sensors with high sensitivity are discussed.
\end{abstract}

\section{Introduction.}

Zirconia ceramic is the most common solid electrolyte used in various applications for oxygen sensors for the automotive industry, metallurgical, glass and cement industries, gas pumps for removing oxygen traces from the gases used in special industrial processes and fuel cells. Their utilisation opened a new way for optimisation of oxygen (air)/fuel ratios and made automotive and industries more environment friendly due to its adequate level of oxygen ion conductivity and desirable stability in both oxidising and reducing atmospheres [1, 2]. Generally $\mathrm{ZrO}_{2}-8 \mathrm{~mol} \% \mathrm{Y}_{2} \mathrm{O}_{3}$ (YSZ) solid electrolytes exhibiting a conductivity of about $0.10 \Omega^{-1} \mathrm{~cm}^{-1}$ at $1000^{\circ} \mathrm{C}$ and about $3 * 10^{-}$ ${ }^{5} \Omega^{-1} \mathrm{~cm}^{-1}$ at $400^{\circ} \mathrm{C}$, corresponding to an activation energy of $96 \mathrm{kJmol}^{-1}$ are used. To improve the ionic conductivity over a large temperature range, different methods have been proposed :

a) Partial or total replacement of $\mathrm{Y}_{2} \mathrm{O}_{3}$ with $\mathrm{Sc}_{2} \mathrm{O}_{3}[3,4]$. A maximum electrical conductivity was observed corresponding to the composition $\left(\mathrm{Y}_{0.5} \mathrm{Sc}_{0.5}\right) \quad 0.3 \mathrm{Zr}_{0.7} \mathrm{O}_{1.85}$. For these samples, no intermediate arc was observed on the complex impedance spectra. Unfortunately the conductivity decreases with holding time caused by some structural modifications [5].

b) Replace classical sensors with new planar sensors developed using ceramic membranes and multipackaging technology [6-10].

c) Utilisation of nanomaterials to reduce the diffusion and transport distances. The existing data on the influence of the crystallite/particle size on the conductivity of YSZ are contradictory. Jiang et al in [11] reported activation energies for grain and grain boundary conduction $(0.95$ and $1.2 \mathrm{eV})$ in agreement with values for conventional materials. Mondal and Hahn [12] prepared nanocrystalline $\mathrm{ZrO}_{2}\left(2-3 \mathrm{~mol} \% \mathrm{Y}_{2} \mathrm{O}_{3}\right)$ ceramics with average grain particle about 35-50nm. The activation energy for bulk $(0.85 \pm 0.05 \mathrm{eV})$ and grain boundary conductivity $(1.0 \pm 0.1 \mathrm{eV})$ as well as the absolute values 
of conductivities were similar to those of conventional ceramics. On the contrary, Kosaki et al [13], investigating YSZ $\left(16 \mathrm{~mol} \% \mathrm{Y}_{2} \mathrm{O}_{3}\right)$ thin films with mean grain size in the range $10-200 \mathrm{~nm}$, found that nanocrystalline materials exhibited a two to three orders of magnitude increase in conductivity compared to polycrystalline and single crystalline materials. An activation energy of about $0.93 \mathrm{eV}$ for the grain boundary conductivity was found. The specific grain boundary conductivity increases sharply with decreasing grain size. It was also reported that the addition of $\mathrm{Al}_{2} \mathrm{O}_{3}$ may reduce the specific grain boundary [14-16]. A model explaining the influence of the grain sizes on the bulk and grain boundary conductivity was proposed in [17].

Zirconia ceramics are remarkable engineering materials with properties, which are particularly suited to high sensitivity pressure sensors due to their higher mechanical strength, fracture toughness, and elastic properties compared to other ceramic materials [1]. PSZ, TZP and aluminazirconia composite, with a flexural strength three times higher than alumina, can broaden the pressure range already covered either towards low and high pressures [18]. It is also important to note that YTZP ceramics have lower activation energy for the ion conduction opening the field for their utilisation at temperatures below $500^{\circ} \mathrm{C}[19,20]$.

Different chemical, physical, mechanical or mixed routes were used to synthesise the initial YTZP nanopowders. Chemical processes such as co-precipitation, sol-gel and hydrothermal routes were reported to produce nanocrystalline powders with high productivity and controlled chemical composition and homogeneity [21-24]. In particular, the hydrothermal route presents some advantages such as it being an environmentally friendly one-step process avoiding subsequent calcinations, having lower energy consumption with control of the crystallite and particle sizes and shapes [25-29].

The aim of the paper is to study the influence of the synthesis and processing parameters on the ion conduction of YTZP nanomaterials and the characteristics of gauges for pressure sensors.

\section{Experimental procedure.}

YTZP powders $\left(\mathrm{ZrO}_{2}\right.$ doped with $\left.3.5 \mathrm{~mol} \% \quad \mathrm{Y}_{2} \mathrm{O}_{3}\right)$ have been synthesized by hydrothermal treatment of the precursor suspensions in a 1.2L Teflon autoclave (CORTEST, USA) for various times in the temperature range $110-250^{\circ} \mathrm{C}$, using ammonia as mineraliser. The detailed synthesis procedure was described in [30]. Chemical quantitative analysis was performed by ICP (Spectroflame). The phase evolution was analysed by XRD spectroscopy and mean crystallite sizes of nanophases vs. synthesis parameters were calculated according to the Sherrer formula from the broadening of the characteristic peaks. SEM and TEM methods were used to examine powder morphology. The specific surface area (BET method) and picnometric densities were used also for characterisation of the powders obtained after washing in water and ethanol and filtering. Mathematical modelling of the process was proposed in order to control the crystallite and grain sizes so that nanopowders with desired and reproducible characteristics can be obtained.

YTZP compacts were obtained after uniaxial pressing at $100 \mathrm{MPa}$ and sintering. The sintering regime was established following microscopic studies of the heating stage. YTZP membranes were produced using a EE-SOTA 1722 tape casting machine in organic media. Menhaden fish oil Z-3 was used as the dispersant, polyvinilbutyral grade B-98 as the binder, butyl benzyl phthalate S 160 and polyalkylene glycol (PG) were used as plasticizers with xylene (X) and ethyl alcohol (EA) as the solvent. The powder was first dispersed by planetary milling for 24 hours. The speed (66 rpm) was about $0.5 \mathrm{~N}_{\mathrm{c}}$, where the critical speed was calculated according to $\mathrm{N}_{\mathrm{c}}=76.6$ (D) ${ }^{1 / 2}$ for a mill diameter of $30.5 \mathrm{~cm}$. After dispersion was complete, the two plasticizers and the binder were added and additionally milled 24 hours to get the desired homogeneous mixture. The mixture was filtered onto a polypropylene foil and the viscosity was measured using a Brookfield viscometer RV4. From 
the filtered suspension, tapes of width of $14.5 \mathrm{~mm}$ and thickness of $42-50$ microns were cast. The casting pressure $(2 \mathrm{psi})$ and tape speed $(15 \mathrm{~m} / \mathrm{min})$ were constant. Membranes with various thicknesses were obtained after sintering in an electrical chamber furnace (CARBOLITE) in normal atmosphere at temperatures up to $1500^{\circ} \mathrm{C}$. The influence of the additives and sintering parameters on the density and microstructure of membranes was studied.

Sintered pellets and membranes were metallised with silver paste and the ionic conductivity was studied by impedance spectrometry. Results on volume and grain boundary contributions are presented showing an important contribution of the grain boundaries in zirconia-based nanomaterials and the expected impact on the development of new oxygen sensors.

Ruthenate pastes were also used to obtain resistive thick films on the YTZP membranes by screen printing. These composite materials were used as mechanical pressure gauges and the gauge factor, noise index, temperature coefficient of resistance and long-term stability were analysed by specialised computer-controlled according to the Quan Tech method.

A general flow sheet of the experimental method is presented in figure 1.

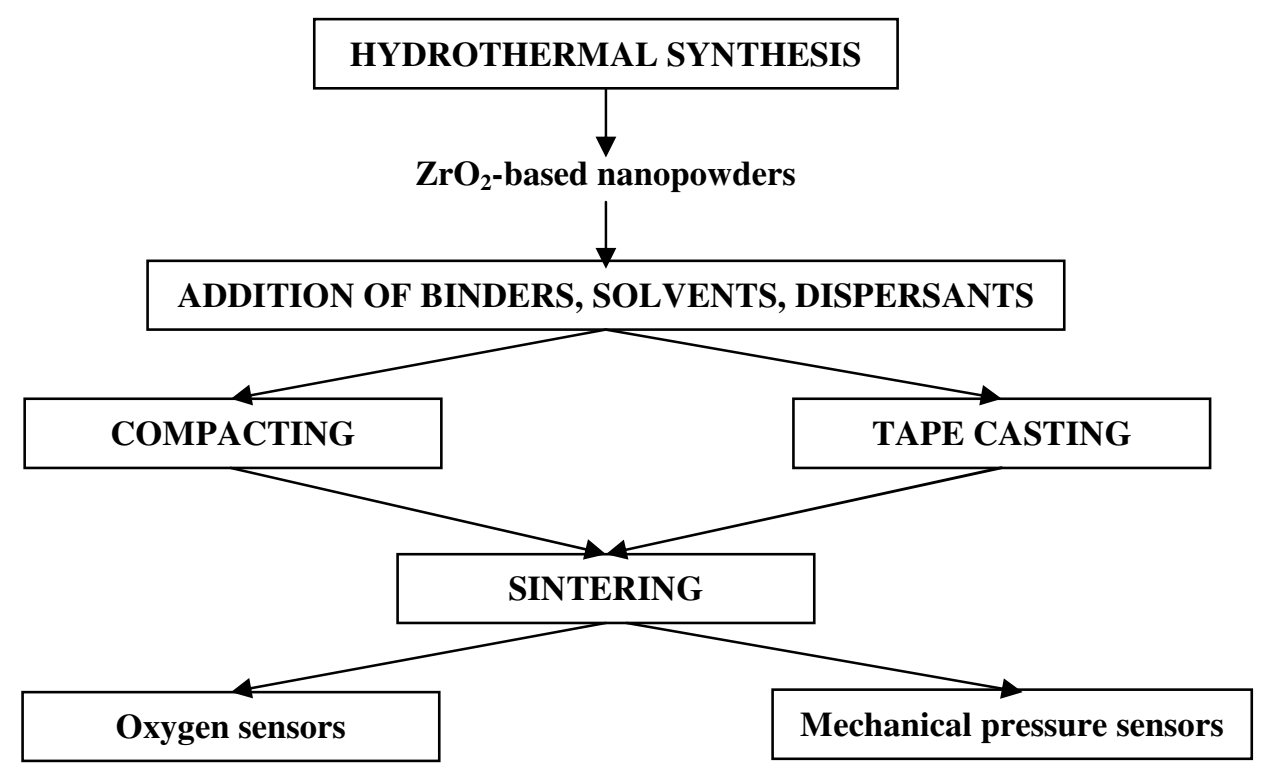

Fig. 1. General flow sheet for the development of zirconia-based sensors

$\mathrm{Y}_{2} \mathrm{O}_{3}-\mathrm{ZrO}_{2}$ nanopowders. The influence of the initial solution $\mathrm{pH}$, temperature, time and solute concentration on the mechanism and kinetic of YTZP formation has been studied in detail [29-31]. It could be observed that $\mathrm{pH}$ is the main parameter controlling the $\mathrm{Y}_{2} \mathrm{O}_{3} / \mathrm{ZrO}_{2}$ molar ratio and nucleation mechanism while time and temperature have a higher influence on the crystallite growth and agglomeration.

The correlation between mean crystallite sizes $\left(\mathrm{d}_{111}\right)$ and synthesis parameters $(\mathrm{pH}$ and temperature) are respectively given in fig. 2 and can be calculated from the equation

$$
\mathrm{d}_{111}=-7.704+0.169 \mathrm{pH}+0.109 \mathrm{~T}
$$




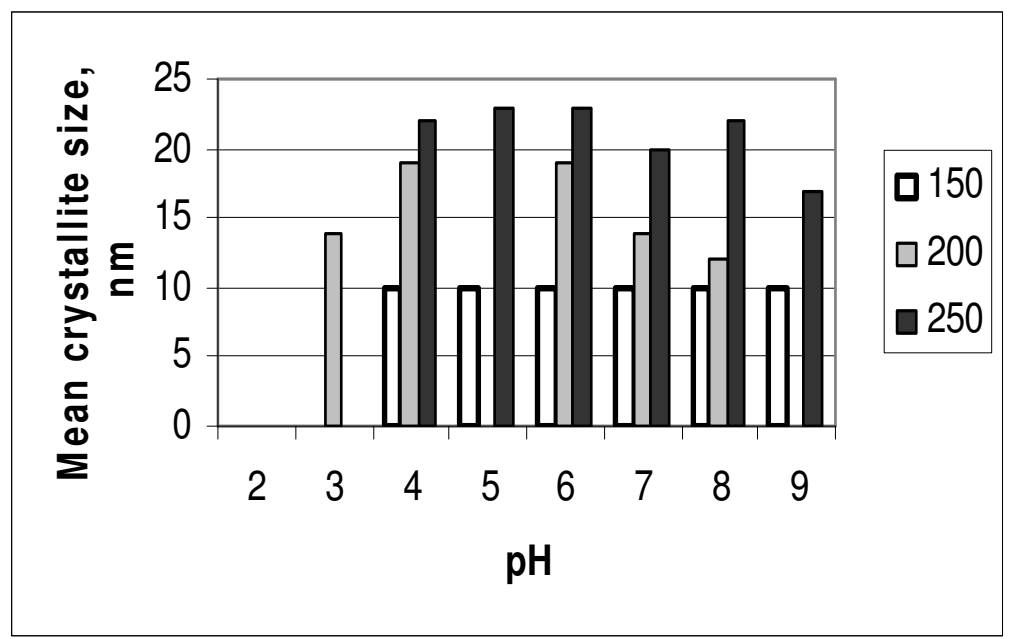

Fig. 2. Mean crystallite sizes of YTZP powders

The formation of YTZP took place by hydrothermal crystallisation of amorphous zirconia precipitated. In the TEM presented in fig. 3, it can be observed that powders preserve a structure similar to the chain structure of hydrous zirconia. This explains also the high BET specific area obtained for different synthesis conditions (table 1). Note that commercial TOSOH powders (code HSY 3T) have a BET specific surface area of $8.5 \mathrm{~m}^{2} / \mathrm{g}$ according to the company certificate.

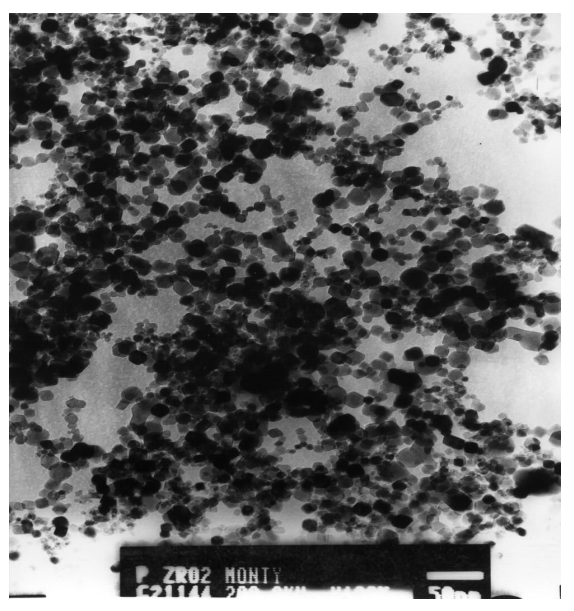

Fig. 3. TEM of $\mathrm{ZrO}_{2}$ powder

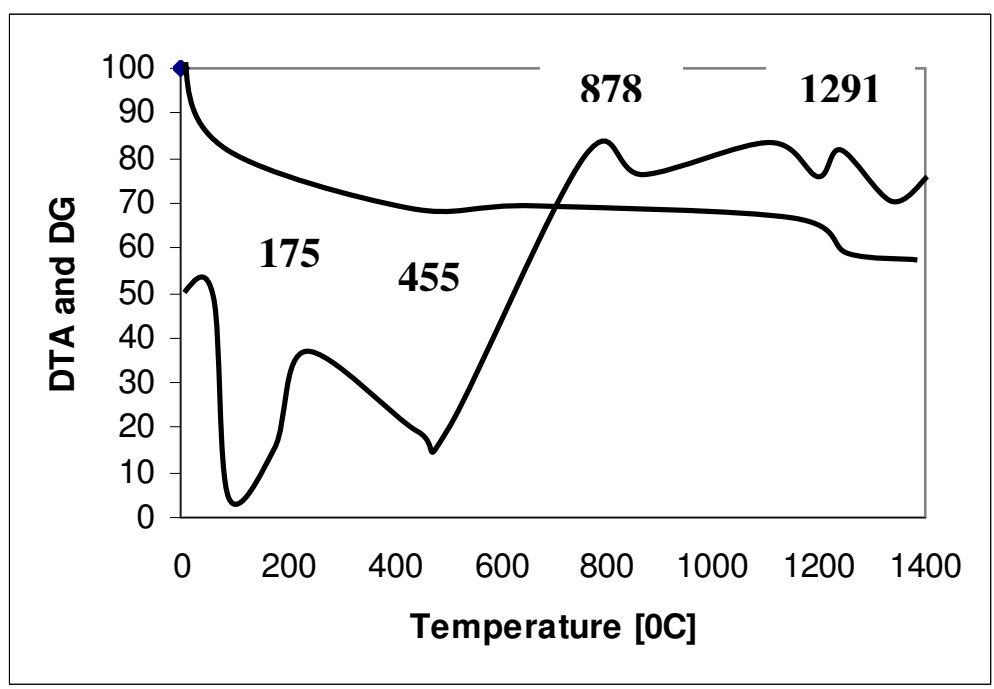

Fig. 4. DTA and TG analysis of YTZP powders

\begin{tabular}{|l|l|l|l|}
\hline Sample & $\begin{array}{l}\text { BET specific } \\
\text { area }\left[\mathrm{m}^{2} / \mathrm{g}\right]\end{array}$ & $\begin{array}{l}\text { Picnometric } \\
\text { density }\left[\mathrm{g} / \mathrm{cm}^{3}\right]\end{array}$ & Synthesis conditions \\
\hline HZYS-1 & 200.1053 & 4.995 & Ammonia mineraliser, 0.02 M Zr, 2 h, 250 $\mathrm{C}$ \\
\hline HZYE-2 & 200.5782 & 5.012 & Urea mineraliser, 0.02 M Zr, 2 h, 250 ${ }^{\circ} \mathrm{C}$ \\
\hline HZYE-3 & 184.9276 & 5.197 & Urea mineraliser, 0.1 M Zr, 2 h, 250 $\mathrm{C}$ \\
\hline
\end{tabular}

Table 1. Specific surface and picnometric densities of powders

Some hydrogen bonding still exists as can be seen from the complex thermal analysis (fig. 3 ).

A model was proposed to predict the crystallite sizes in hydrothermal conditions:

$\mathrm{r}_{\mathrm{m}}=\mathrm{r}_{0}(1-\alpha)^{1 / 3} ; \mathrm{r}_{0} \approx\left(3 \mathrm{k}_{\mathrm{B}} / 4 \pi \mathrm{r}_{0}\right)^{1 / 3}\left(\mathrm{P}_{\mathrm{e}}\right)^{1 / 3}\left(-\ln \mathrm{K}_{\mathrm{h}, \mathrm{g}}\right)^{-1 / 3}\left[\ln \left(1 /\left(1-\left(\mathrm{P}_{\mathrm{e}} / \mathrm{S}_{0}\right)\right)\right]^{1 / 3}\right.$ 
where $\alpha$ is the experimental crystallisation degree, $\mathrm{k}_{\mathrm{B}}$ is Boltzmann's constant, $\mathrm{K}_{\mathrm{h}, \mathrm{g}}$ is the hydrolysis constant, $\mathrm{P}_{\mathrm{e}}$ the precursor concentration $\mathrm{M}(\mathrm{OH})_{\mathrm{z}}$ and $\mathrm{S}_{0}$ the initial metal concentration.

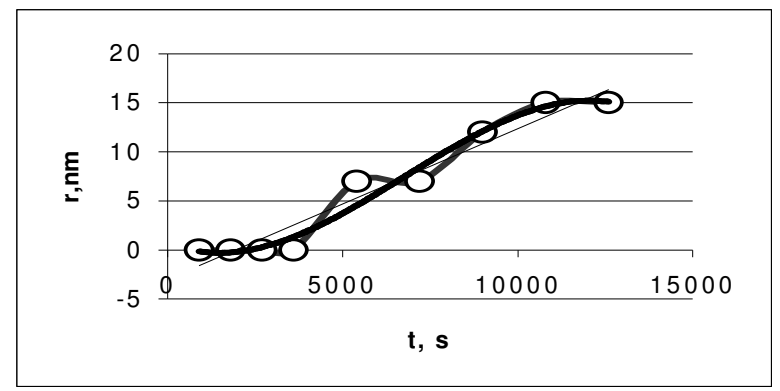

Taking the kinetic constant value $k=0.12075 \mathrm{~s}^{-1}$, one may calculate as real solutions of the equations given before $r_{0} \approx 0.35 \mathrm{~nm}$ and $r_{m} \approx 5.13 \mathrm{~nm}$. Comparison of the experimental data with the predicted values (Fig.5) shows good agreement only for low temperatures and times, probably due to increase of the agglomeration degree at high temperatures and time.

Fig. 5. Experimental (०) and calculated values of nuclei radius

YTZP compacts. Sintered compacts have been obtained after uniaxial pressing at $100 \mathrm{MPa}$ and sintering. The dynamic sintering curves obtained by the heating stage microscopy (Fig. 6) show two shrinkage intervals, the first from room temperature to approximately $550^{\circ} \mathrm{C}$ related to thermal decomposition observed by thermal analysis and the second at $1400^{\circ} \mathrm{C}$ corresponding to sintering, with a total shrinkage at $1400{ }^{\circ} \mathrm{C}$ of $28 \%$. To eliminate the chemically bonded water, powders have been additionally attrition milled for 2 hours in acetone. Compacts with densities higher than $96 \%$ of the theoretical and grain sizes around $200 \mathrm{~nm}$ have been obtained (fig. 7).

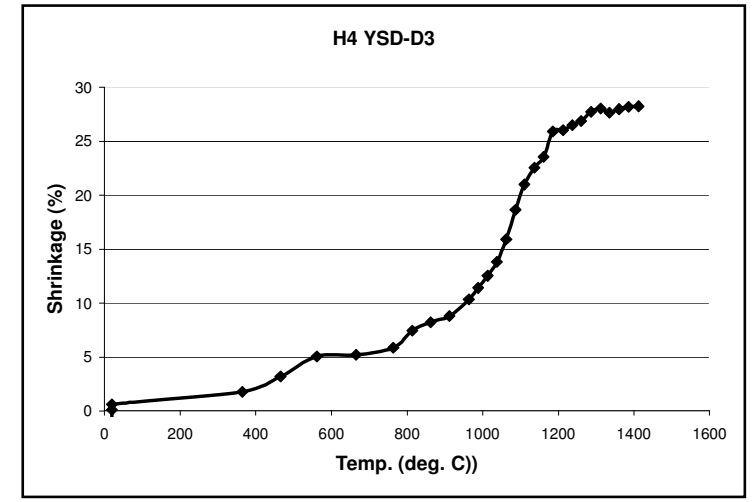

Fig. 6. Dynamic sintering curves

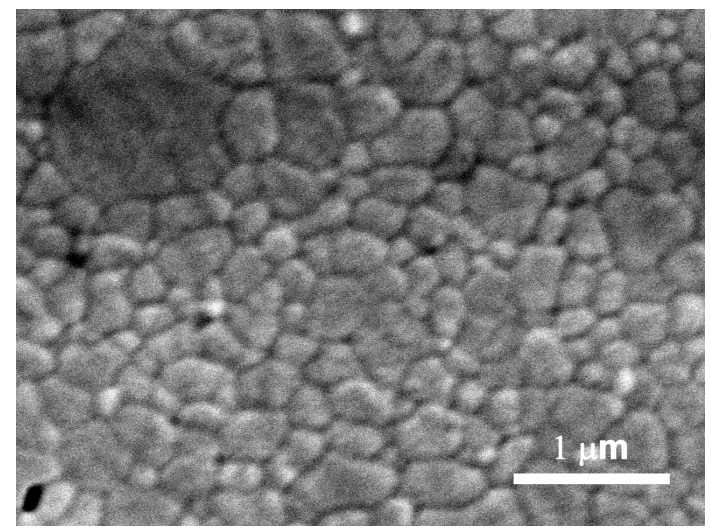

Fig. 7. SEM of a sintered compact $\left(2 \mathrm{~h}, 1400^{\circ} \mathrm{C}\right)$

\begin{tabular}{|l|l|l|l|l|l|l|l|l|l|}
\hline $\begin{array}{l}\text { Components } \\
\text { (wt.\%) }\end{array}$ & H4YS & Z-3 & X & EA & B-98 & S-160 & PG & $\begin{array}{l}\text { Viscosity, } \\
\text { cP }\end{array}$ & $\begin{array}{l}\text { Filter size, } \\
\text { mesh }\end{array}$ \\
\hline Test 1 & 61.94 & 1.24 & 15.31 & 15.31 & 3.09 & 1.55 & 1.55 & 4500 & 180 \\
\hline Test 2 & 61.66 & 1.24 & 15.28 & 15.12 & 3.01 & 2 & 1.55 & 3500 & 270 \\
\hline
\end{tabular}

Table 2. Parameters for the tape casting of YTZP membranes

YTZP membranes. The parameters used for the tape casting of membranes are given in table 2.

Sintering experiments made to establish the sintering conditions for obtaining membranes showing that densities over $96 \%$ of the theoretical value and a total shrinkage of $12.8 \%$ are reached after 2 hours treatment in similar conditions with the pressed compacts (fig. 8). 

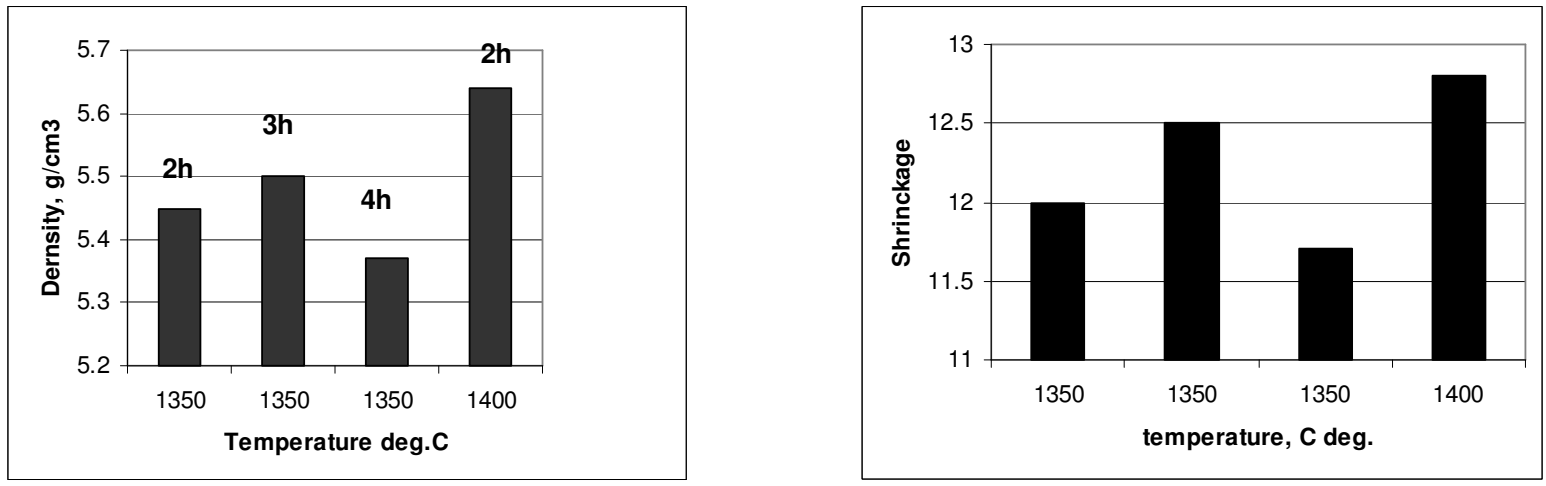

Fig. 8 Densities and shrinkage of sintered YTZP membranes

Ionic conductivity. Using the procedure described above dense sintered samples with different Yttria content were prepared. The contributions of bulk and grain boundaries on the total ionic conductivity were calculated from the impedance spectra of samples. Table 3 presents the calculated activation energy of ionic conductivity.

\begin{tabular}{|c|c|c|c|c|}
\hline Sample & $\mathrm{mol}_{2} \mathrm{Y}_{2} \mathrm{O}_{3}$ & $\mathrm{Q}_{\mathrm{i}}(\mathrm{kJ} / \mathrm{mol})$ & Grain sizes, $\mathrm{nm}$ & Observation \\
\hline E1 & 7.5 & 110 & 625 & Polycrystalline \\
\hline E3 & 3 & 97.5 & 524 & Polycrystalline \\
\hline E4 & 3 & 86 & 393 & Polycrystalline $\left(0.25\right.$ mol $\left.\mathrm{Al}_{2} \mathrm{O}_{3}\right)$ \\
\hline E5 & 4 & 90 & 603 & Polycrystalline \\
\hline SC3 & 3 & 84 & & Single crystal \\
\hline
\end{tabular}

Table 3. Calculated activation energy of ionic conductivity for different samples

Modelling the ionic conductivity of YTZP nanomaterials was performed by considering the "brickboundary" model and supposing the conduction of oxygen ions takes place via the bulk of grains with main size $a$ (circuit 1), passing perpendicularly through the grain boundary (circuit 2) and parallel with the grain boundaries of thickness $\delta$ ("short-circuit" 3). Calculation results for homogenous grain sizes, taking the grain boundary thickness $\delta=1 \mathrm{~nm}$ and noting $a=\alpha \delta$ are presented in fig. 9.
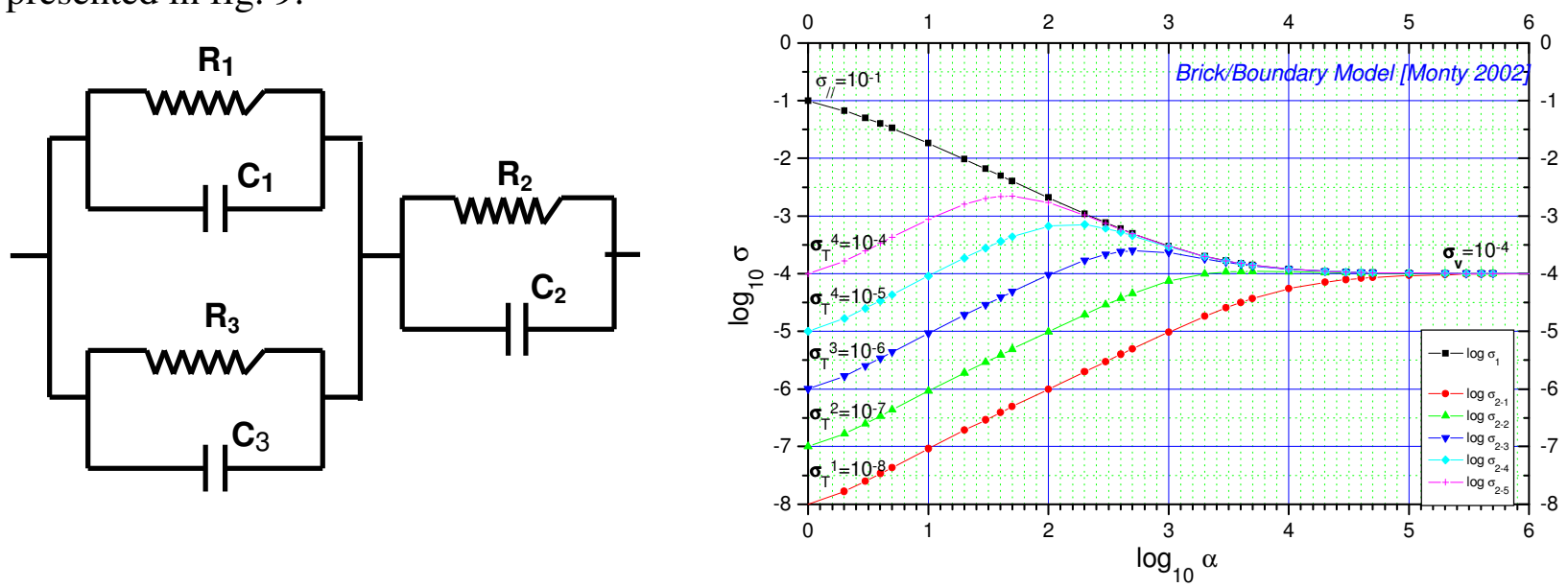

Fig. 9. Equivalent circuit of the proposed Brick-boundary model and calculated total ionic conductivity for different grain sizes

From the model developed it may be concluded that grain boundaries can increase the total ionic conductivity of Yttria-doped zirconia by a short circuit effect leading to an apparent bulk conductivity higher than that of single crystals of similar composition. This effect increases while the grain size diminishes. It is negligible for large grain sizes. The barrier effect is increasingly 
important as grain size diminishes. It becomes negligible for large grain sizes. The total conductivity of polycrystalline samples as a function of grain size has a maximum that can be higher than the ionic conductivity of single crystals of same composition.

Zirconia pressure gauges. Sensing elements used for detecting mechanical pressures made of YTPZP would have some improved characteristics as Y-TPZ has a higher mechanical strength and a lower elastic modulus than alumina. To transform the mechanical deformation into an electrical signal, thick resistor films are printed and fired on the ceramic substrate (diaphragm). Fig. 10 presents the schematic representation of the device. The compatibility of different conductive pastes normally used for alumina substrates were first tested in order to avoid chemical interactions with the substrate. The XRD spectra of the resistors that were fired on $\mathrm{Al}_{2} \mathrm{O}_{3}$ and $\mathrm{ZrO}_{2}$ substrates are shown in Figs. 11.a to 11.d. The peaks of $\mathrm{RuO}_{2}$ and the ruthenates phase are denoted " $\mathrm{R}$ " and

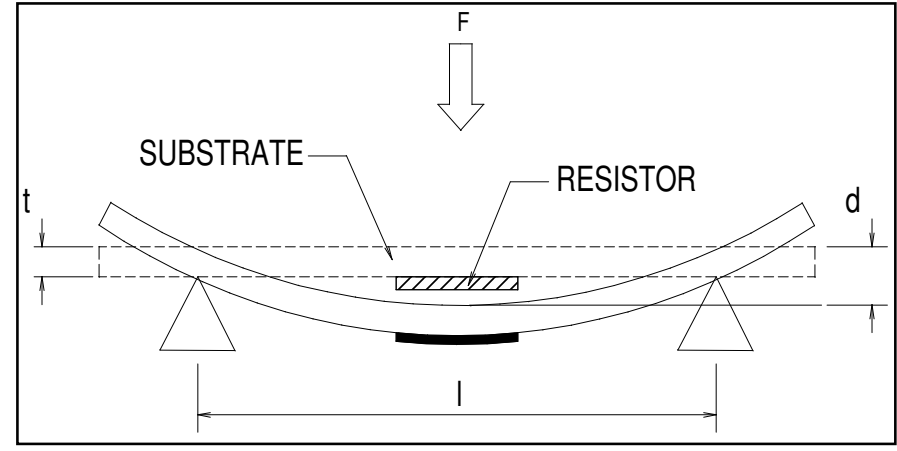

Fig. 10. Device for gauge factor evaluation

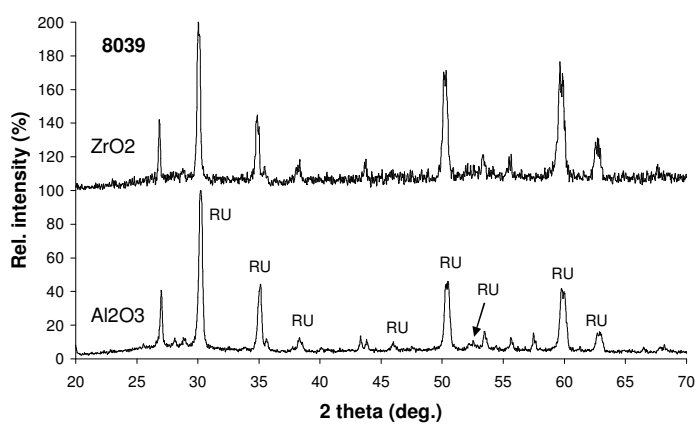

Fig. 11.a. X-ray spectra of 8039 resistors, fired on $\mathrm{Al}_{2} \mathrm{O}_{3}$ and $\mathrm{ZrO}_{2}$ substrates. Peaks of ruthenate phase are denoted "RU"

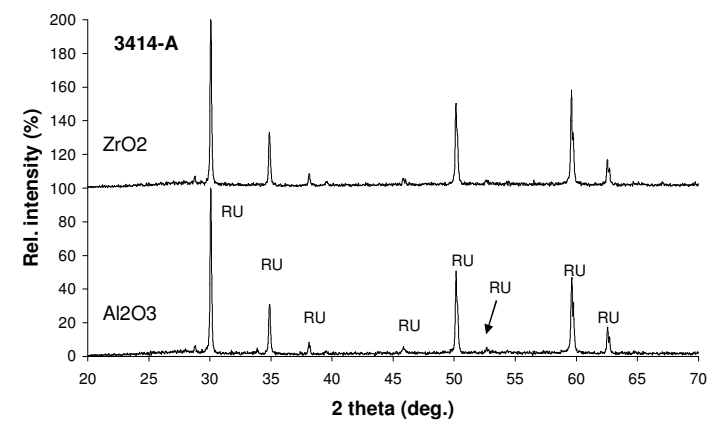

Fig. 11.c. X-ray spectra of 3414-A resistors, fired on $\mathrm{Al}_{2} \mathrm{O}_{3}$ and $\mathrm{ZrO}_{2}$ substrates.
"RU", respectively. The spectra are nearly the same, which confirms the compatibility of the $10 \mathrm{kohm} / \mathrm{sq}$. resistors tested with the zirconia ceramics. For each type of composite material obtained it was further determined that the main sensing parameters: sheet resistivity, cold $\left(-25^{\circ} \mathrm{C}\right.$ to $\left.25^{\circ} \mathrm{C}\right)$ and hot $\left(25^{\circ} \mathrm{C}\right.$ to $\left.125^{\circ} \mathrm{C}\right)$ temperature coefficients of resistivity (TCR), noise indices and gauge factor the relative change in resistance $(\Delta \mathrm{R} / \mathrm{R})$ and the strain $(\Delta \mathrm{l} / \mathrm{l})$.

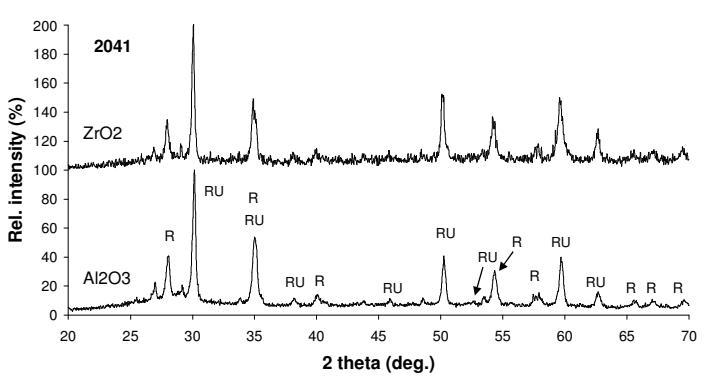

Fig. 11.b. X-ray spectra of 2041 resistors, fired on $\mathrm{Al}_{2} \mathrm{O}_{3}$ and $\mathrm{ZrO}_{2}$ substrates. Peaks of $\mathrm{RuO}_{2}$ and ruthenate phase are denoted "R" and "RU", respectively.

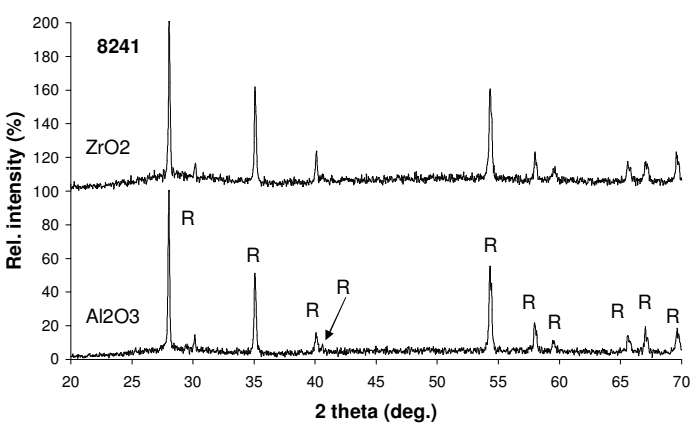

Fig. 11.d. X-ray spectra of 8241 resistors, fired on $\mathrm{Al}_{2} \mathrm{O}_{3}$ and $\mathrm{ZrO}_{2}$ substrates. 
The evolution of noise indices and gauge factors of resistors on typical 96\% alumina and YTZP membranes are presented in fig. 12 and 13.

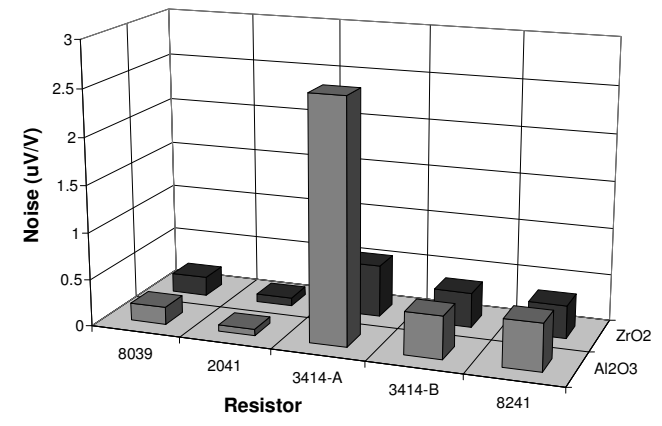

Fig. 12: Noise indices of resistors, fired on the $\mathrm{Al}_{2} \mathrm{O}_{3}$ and $\mathrm{ZrO}_{2}$ substrates

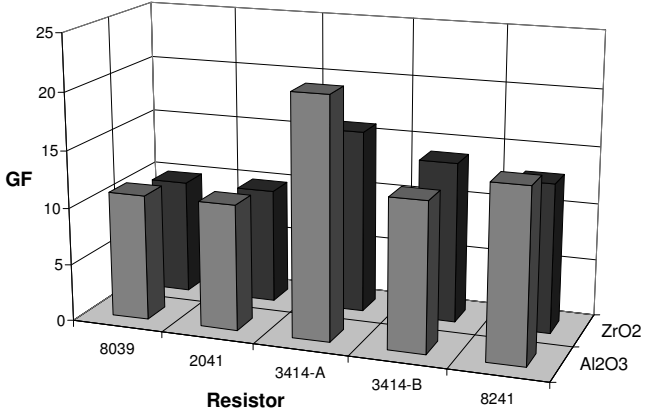

Fig. 13: Gauge factors of resistors, fired on the $\mathrm{Al}_{2} \mathrm{O}_{3}$ and $\mathrm{ZrO}_{2}$ substrates

These results indicate that the evaluated hick-film resistors are compatible with zirconia ceramics. The sensitivity of the alumina and YTZP sensors made using these membranes are presented in table 4 and figure 14. It can be observed that zirconia pressure sensors have a much higher sensitivity and stability compared to classical alumina ones and consequently they can be used for measuring pressures in a larger pressure and temperature range.

\begin{tabular}{|c|c|c|}
\hline \multirow{2}{*}{ Temperature $\left({ }^{0} \mathrm{C}\right)$} & \multicolumn{2}{|c|}{ Sensitivity $(\mathrm{mV} / \mathrm{V} / \mathrm{bar})$} \\
\cline { 2 - 3 } & YTZP & $\mathrm{Al}_{2} \mathrm{O}_{3}$ \\
\hline-35 & 2.51 & 0.95 \\
\hline-25 & 2.49 & 0.94 \\
\hline 25 & 2.68 & 0.92 \\
\hline 100 & 2.46 & 0.84 \\
\hline 150 & 2.46 & 0.82 \\
\hline $\begin{array}{c}\text { Temperature coefficient of } \\
\text { sensitivity }\left(\mathrm{ppm} /{ }^{0} \mathrm{C}\right)\end{array}$ & -107 & -737 \\
\hline
\end{tabular}

Table 4. Comparative values of the sensitivity of alumina and YTZP based pressure sensors
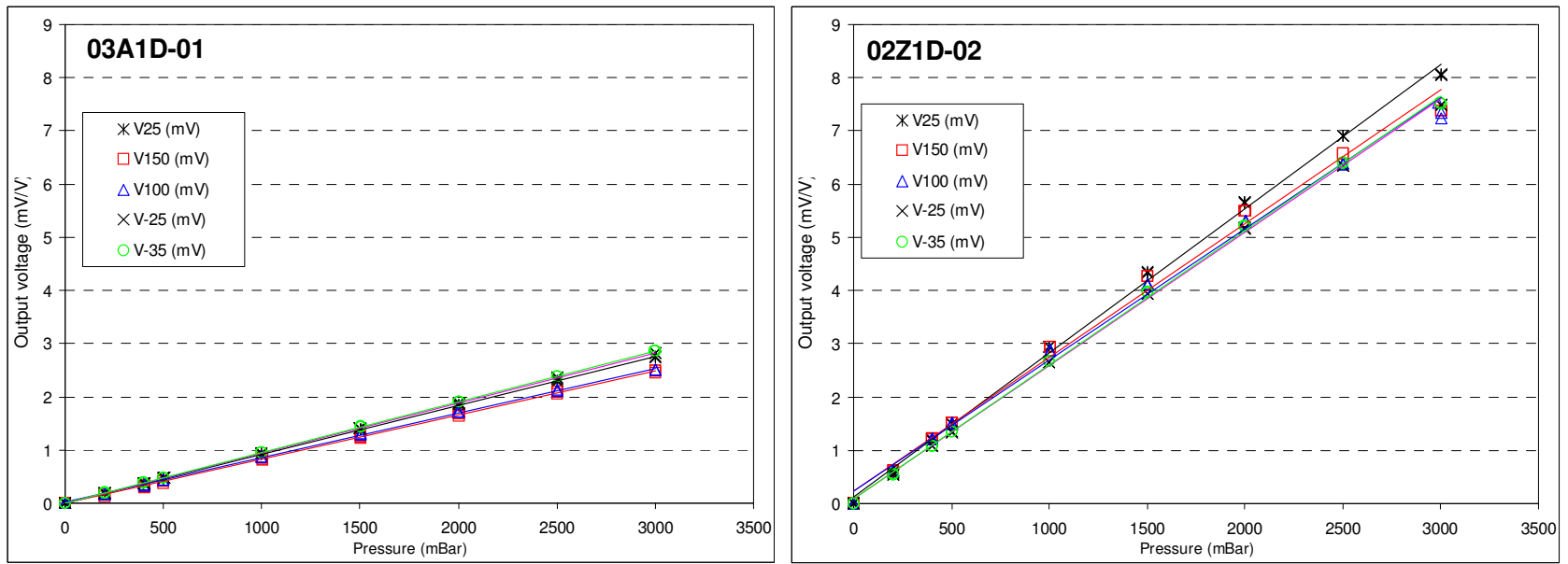

Fig. 14. Sensitivity of alumina (left) and YTZP-based (right) pressure sensors

Summary. Yttria-doped zirconia nanopowders were obtained using the hydrothermal crystallisation of hydrous oxides in-situ precipitated from soluble inorganic salts. High purity nanopowders with specific surface area near $200 \mathrm{~m}^{2} / \mathrm{g}$ were obtained. The powders agglomerates preserve the chain structure of initial hydrous zirconia and milling in acetone was performed for complete elimination 
of structural water. These powders have been have been used to obtain sintered pellets by compaction, or membranes by tape casting with controlled Yttria content and grain sizes with densities over $95 \%$ after sintering.

These materials were used to model the size dependence of ionic conductivity. From the model proposed it might be concluded that the total conductivity of polycrystalline samples as a function of grain size has a maximum that can be higher than the ionic conductivity of single crystals of the same composition at grain sizes around $20 \mathrm{~nm}$. At lower grain sizes, the barrier effect of the grain boundaries becomes more important than the expected short-circuit effect obtained by the ionic conduction parallel with the grain boundaries directions. These effects are dependant on the microchemistry of grain boundaries. The global composition leading to the best results at temperatures below $500^{\circ} \mathrm{C}$ is close to $3-4 \%$ mol Y2O3 and not $8-9 \%$ mol Y2O3 as it is the case at usual temperatures of the order of $1000^{\circ} \mathrm{C}$.

The potential of YTZP nanomaterials resulting from their superior mechanical characteristics was also used in producing pressure gauges with higher sensitivity and thermal stability. The results indicate that screen printed thick rutenate resistor films normally used for alumina substrate are compatible with zirconia ceramics. The comparison of the sensitivity of alumina and YTZP sensors made using membranes shows that zirconia pressure sensors have a much higher sensitivity and stability compared to classical alumina ones and consequently they can be used for measuring pressures in a larger pressure and temperature range.

\section{Aknowledgements.}

The present paper is based on the results obtained in the frame of the NATO SfP project 974054 "Zirconia Nanomaterials", granted by the NATO Scientific and Environmental Affairs Division. One of the authors (Dr. Robert Piticescu) expresses special thanks to Prof. Witold Lojkowski and his group from High Pressure Research Centre UNIPRESS Warsaw, Poland for performing BET specific surface area and picnometric densities measurements and for fruitful discussions on the subject.

\section{References}

[1] Stevens, R., Zirconia and zirconia ceramics, published by Magnesium Elektron Ltd., printed by Lithio 2000, Twickenham, UK

[2] Gope, W., Reinhardt, G., Rosch, M., Trends in the development of solid state amperometric and potentiometric high temperature sensors, Solid State Ionics 136-137 (2000), p. 519-531

[3] Ciachi, F. T. , Badwall, S. P. , Drennan, J., J. Eur. Ceram. Soc., 7, p. 185-95 (1991)

[4] Ciachi, F. T. , Badwall, S. P., Drennan, J.,J. Eur. Ceram. Soc. 7, p. 197-206 (1991),

[5] H.Yamamura, T. Mori, T. Atake, Proc. of US-Japan work shop on Electrically Active Ceramic Interfaces, March 17-19, 1998, Massachusets Inst. of Technology, USA, p. 159-162.

[6] K. Tatenuma, G. Terakado, T. Taguchi et al, Proc of US-Japan Workshop on Electrically Active Ceramic Interfaces, March 17-19, 1998, Massachusetts Inst. of Technol., USA, p. 213-216

[7] Gibbson, R.W., Kumar, R.V., Fray, D.J., Novel sensors for monitoring high oxygen concentrations, Solid State Ionics 121 (1999), p. 43-50

[8] Komachiya, M., Suzuki, S., Fujita, T., Tsuruki, M., Ohuchi, S., Nakazawa, T., Limiting-current type air-fuel ratios sensor using porous zirconia layer without inner gas chamber: proposal for a quick-startup sensor, Sensors and Actuators B73 (2001), p. 40-48

[9] Menil, F., Coillard, V., Debeda, H., Lucat, C., A simplified model for the evaluation of the electrical resistance of a zirconia substrate with co-planar electrodes, Sensors and Actuators B77 (2001), p. 84-89

[10] Ivers-Tiffee, E., Hardtl, K.H., Menesklou, W., Riegel, J., Principles of solid state oxygen sensors for lean combustion gas control, Electrochimica Acta 47 (2001), 807-814 
[11] Jiang, S., Schulze, W. A., Amarakoon, V. R., Stangle, G. C., J. Mater. Res., 12, pp.2374 (1997)

[12] Mondal, P.,Hahn, H., Ber. Bunsenges, Phys.-Chem., 101, pp.1765 (1997)

[13] Kosacki, I., Colomban, P., Anderson, H. V., Proc of US-Japan Workshop on Electrically Active Ceramic Interfaces, March 17-19, 1998, Massachusetts Inst. of Technol., USA, p 180-188

[14] K. Guo, C. Q. Tang, R. Z. Yuan, J. Am. Ceram. Soc. 77(1), pp. 25-32 (1994)

[15] Filal, M., Petot, C., Mockhah, M., Chateau, C., Carpentier, J.L., Ionic Conductivity of yttrium doped zirconia and the composite effect, J. Eur. Ceram., Soc., 80 (1995), p.27-35

[16] Cheikh, A., Madani, A., Touati, A., Boussetta, H., Monty, C., Ionic conductivity of zirconia based ceramics: from single crystals to nanostructured materials, J. Eur. Ceram. Soc., Vol. 21 (2001), p. 1837-1841

[17] Monty, c., About Ionic Conductivity/Diffusion relashionship in yttria doped zirconia, Ionics (under press)

[18] Satoh, S., Takatsuji, Y., Katoh, F., Hirata, H., Proc. International Symposium on Microelectronics, ISHM'91, October 21-23 (1991), Orlando, Florida, , p. 148-152

[19] Wepner, W., Tetragonal zirconia polycrystals-a high performance solid oxygen ion conductor, Solid State Ionics 52 (1992), p. 15-21

[20] Garzon, F.H., Brosha, E.L., US Patent 5,695,624, December 9, 1997

[21] Mazdiyasni, K.S., Lynch, C.T., Smith, J.S., J. Am. Ceram. Soc. 50 (1967), p. 532

[22] van de Graaf, M.A.C.G., Burggraaf., A.J., in Advances in Ceramics, Science and Technology of Zirconia II, vol. 12, 1994, ed. by Clausen, N., Ruhle, M., and Heuer, A., The American Ceramic Society, OH, p. 744

[23] Somyia, S., in Ceramics Today-Tommorow's Ceramics, vol. 66B, 1991, Elsevier, p. 997

[24] Bucko, M.M., Haberko, K., Farayan, M., J. Am. Ceram. Soc., 78 (1995), p.3397-41

[25] Kriygsman, P.,The Hydrothermal Synthesis of Ceramic Powders, 1992, ed. By Chemical Eng. Comp. AG. Niederscherli, Switzerland

[26] Yoshimura, M., Somyia, S., Hydrothermal synthesis of crystallized nano-particles of rare earth-doped zirconia and hafnia, Mater. Chem. And Physics, 61 (1999), p. 1-8

[27] DellÁgli, G., Mascolo, G., Hydrothermal synthesis of $\mathrm{ZrO}_{2}-\mathrm{Y}_{2} \mathrm{O}_{3}$ solid solutions at low temperature, J. Eur. Ceram. Soc., 20 (2000), p. 139-145

[28] Khollam, Y.B., Deshpande, A.S., Patil, A.J., Potar, H.S., Deshpande, S.B., Date, S.K., Synthesis of YSZ powders by microwave-driven hydrothermal route, Mater. Chem. And Physics, 71 (2001), p. 235-241

[29] Piticescu, R.R., Monty, C., Taloi, D., Motoc, A., and Axinte, S., Hydrothermal synthesis of zirconia nanomaterials, J. Eur. Ceram. Soc., 21 (2001), p.2057

[30] Piticescu, R.R., Malic, B., Kosec, M., Motoc, A., Monty, C., Soare, I., Kosmac, T., Dasklober, A., Synhtesis and sintering behaviour of hydrothermally synthesised YTZP nanopowders for ionconduction applications, J. Eur. Ceram. Soc. (under press)

[31] Roxana M. Piticescu, R. R. Piticescu, D.Taloi, V. Badilita "Hydrothermal synthesis of ceramic nanomaterials for functional applications", Nanotechnology, vol. 14, no. 3, February 2003 